\section{Genetics in Madrid}

DuRING a recent visit to Madrid for another purpose, I was able to visit some of my colleagues there, and was delighted to find that research work in genetics was continuing. Prof. I. de Zulueta, in the intervals of hiding the more precious contents of the biological museum in cellars, was continuing his work on the polymorphic beetle Phytodecta variabilis. Prof. Galan, of Salamanca, was very appropriately breeding the 'explosive cucumber', Ecballium elaterium. This plant is hermaphrodite in one half of Spain, diœeious in the other. Crosses between a diceious plant and hermaphrodites from different areas seemed to reveal the existence of 'strong' and 'weak' local races, differing, like those of Lymantria, in respect of sex-determining factors.

Our discussion of these topics was interrupted by an air raid considerably more severe than any of those on London in 1914-18. However, no bombs fell very near us, and at the time I left, the Museo de Ciencias had not yet shared the fate of the University City, the Prado and the Museum of Anthropology. I think that the persistence of de Zulueta and Galan under conditions which are, to say the least, uncongenial for research, deserves to be recorded, and augurs well for the future of biology in Spain.

University College,

J. B. S. HALDANE.

Gower Street,

London, W.C.l.

\section{Neutrino Theory of Light}

ProF. V. FocK ${ }^{2}$ has stated recently in these columns that he has found that the photon operator defined in the Jordan neutrino theory of light is commutable with its conjugate, and has thus claimed an inconsistency in the theory. It may be remarked that Fock's arguments in this connexion are not quite clear. Indeed, if we follow the notation in his note, we get :

$$
\begin{aligned}
\sqrt{ }\left|v v^{\prime}\right|\left(b_{\nu} b_{\nu^{\prime}}-b_{\nu^{\prime}} b_{v}\right)= & \int_{-\infty}^{\infty}\left(\gamma_{\alpha} \dagger \gamma_{\alpha}+\nu+v^{\prime}-\right. \\
& \left.\gamma_{\alpha} \pm \nu^{\prime} \gamma_{\alpha}+v\right) d \alpha .
\end{aligned}
$$

It must not be thought that (1) is zero just because it can be split up into two integrals and the second integral can be transformed to the first by changing $\alpha$ to $\alpha+v^{\prime}$ in it. The splitting of the integral appears to be not justified; when $v+v^{\prime}$ is zero, each of the split integrals is divergent, for each of them represents the number of particles both in the positive states and the negative states. This is in fact the argument which implies $\infty-\infty$.

A careful application of the convergence criteria regarding the finiteness of the number of particles in the positive states and the number of holes in the negative states, presented in a report by Prof. Max Born and myself ${ }^{2}$, will lead to the result that (1) has the value $v$ if $b_{v}$ and $b_{v^{\prime}}$ are conjugate, and has the value zero if it is otherwise. Jordan ${ }^{3}$ has also deduced this result by writing the photon operator in a form that does not involve negative indices.

Indian Institute of Science,

$$
\text { N. S. NAGENDRA NATH. }
$$

\section{Bangalore.}

1 NATURE, 138, 1011 (1936).

Proc. Ind. Acad. Sci., 3, 318 (1936).

2. Phys., 98, 109 (1936).

\section{Breeding Tests and Variations}

IN Nature of January 30, p. 197, Prof. T. F. Dreyer draws certain sweeping conclusions as to genetics and its limitations, from an experiment in which he produced visible abnormality and constitutional defect in 11 locusts by means of environmental treatment during development. He did not breed even an $F 1$ generation.

Prof. Dreyer naively remarks that the abnormalities "remind one strongly of similarly localized (and similarly produced ?) abnormalities in Drosophila, and .we may legitimately assume the abnormality will be hereditary".

Such a statement, in the present state of biology, can only rest on unfamiliarity with the facts. For it is a commonplace of genetics that only breeding tests can distinguish between hereditary and non-hereditary variation; and numerous workers, notably Goldschmidt, have directed attention to the frequent phenomenon of the complete identity of visible effect, in Drosophila and other organisms, of mutations due to genetic change and modifications due to environmental change and not inherited.

Prof. Dreyer's conclusions are thus founded on an elementary but basic methodological error.

$$
\text { Zoological Society, }
$$

Regent's Park, N.W.8.

JuliaN S. HuxLey.

\section{Activity of Corticosteron in the Glucose Test in Rats}

EIGHT days after extirpation of both adrenals, adult rats die in about 5 hours if fed with $2.5 \mathrm{gm}$. glucose (5 c.c. of 50 per cent solution $)^{1}$. This test can be used to titrate adrenal cortical hormone both quickly and accurately.

By this method, the great activity of corticosteron, the active crystalline fraction of cortical extracts, can be clearly shown ${ }^{2}$. If $0.2 \mathrm{mgm}$. or more of corticosteron be injected subcutaneously one hour before the glucose is given, the adrenalectomized rats remain alive. With doses of $0 \cdot 1-0 \cdot 15 \mathrm{mgm}$., about 50 per cent of the rats lived, and with $0.05 \mathrm{mgm}$. or less all the rats died in 3-6 hours (with severe diarrhcea, as in the case of the uninjected rats). The active dose of corticosteron in this test is $0.2 \mathrm{mgm}$. (per rat of $150 \mathrm{gm}$.).

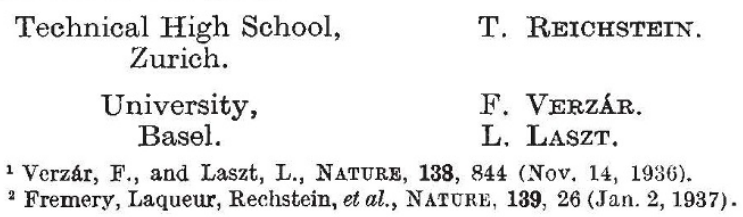

University,
Basel.

\section{Scientific Worthies and Events commemorated on Postage Stamps}

Some time ago ${ }^{1}$, reference was made in these pages to the fact that Ecuador had celebrated the centenary of Darwin's visit on September 16, 1835, by a special issue of postage stamps. These are not the first stamps of scientific interest. In 1923 France issued stamps bearing the head of Louis Pasteur, in 1927 Berthollet and later Pilâtre de Rozier. Louis Blériot and his pioneer flight across the Channel were commemorated in 1934. A recent issue also shows Pasteur at work.

Other countries, too, have issued stamps commemorative of scientific events or famous men of 